\title{
Environmental indicators for acid mine drainage: advances in knowledge and challenges ahead
}

\author{
B.G. Lottermoser University of Tasmania; and Cooperative Research Centre for Optimising Resource \\ Extraction, Australia
}

\begin{abstract}
Environmental indicators are measures to track changes in the quality of the air, water, land and ecological systems. At mine sites, such indicators provide information on conditions and processes that exist or may develop during the life of mine phases and after mine closure. The objectives of this contribution are to review predictive environmental indicators for acid mine drainage (AMD) and to illustrate our advances in knowledge and the challenges ahead.

Since the first scientific observations on AMD processes at mine sites hundreds of years ago, we have gained some phenomenal knowledge on indicators and their application in life of mine planning. Yet, today's AMD indicators still have serious limitations, are riddled with uncertainties that are hard to quantify, or only allow predictions that represent the best estimate of what will happen in the future. The time has come to drastically improve our scientific efforts to precisely predict impacts and closure liabilities on all scales.

The route to greater confidence in the prediction of AMD processes is not through more sophisticated modelling. Our skills at modelling have run ahead of our understanding of the complex mineralogical, geochemical and microbiological processes leading to AMD, and our ability to test models against real data from the laboratory and the field. Improvements will come from better environmental tests and better understanding of the underlying processes at individual mine sites.

There is reason for optimism that the required progress is possible. Such optimism is based on the phenomenal advances in our ability to predict AMD processes and impacts using environmental indicators. However, detailed studies on the design and validity of new predictive AMD indicators are necessary if we are to achieve more cost-effective mine closure and reduce environmental liabilities in the long term. Such progress also requires the application of AMD indicators at the beginning of the mine life cycle and well before mine closure. In future, life of mine plans including closure plans should be based on less verbiage and fragmented environmental knowledge, a greater use of scientific data and environmental indicators, and a much improved knowledge of environmental processes. This has to include the early use of AMD indicators, most appropriately from the exploration stage onwards.
\end{abstract}

\section{$1 \quad$ Introduction}

Indicators are signs or signals that convey messages. They have their value as proxies for measuring conditions that can be difficult or impossible to measure. Indicators have been developed for a range of applications, including environmental monitoring, reporting and prediction. Environmental indicators are to track changes to the quality and condition of the air, water, land and ecological systems - and their resident biota - on various geographic and temporal scales. At mine sites, such indicators provide information on conditions and processes that exist or may develop during the life of mine phases from the exploration (Parbhakar-Fox and Lottermoser, 2011) to the closure stage (Asher and Bell, 1998; Jasper, 2007).

The need for improved understanding of environmental liabilities and risks associated with mining operations has been widely recognised in the mining industry. For example, a number of mining companies have identified that a well organised and implemented approach to the prediction and prevention of acid 
mine drainage (AMD) can have significant financial benefits, with some suggesting that as little as a $10 \%$ reduction in mine closure liability may be worth tens of millions to individual companies:

"A well organised, planned and implemented approach to the prevention of AMD can have significant economic impact on the financial performance of a company like Newmont-just a 10\% reduction in liability is worth tens of millions of dollars in direct benefit to Newmont's global Net Asset Value." Dowd (2006)

Predicting environmental risks is typically not an attribute which is strongly embedded into the development of mineral resources. Yet, a more predictive (and proactive) approach to early environmental characterisation and AMD risk assessment would support more effective management and valuation during mineral processing, subsequent storage of waste and ultimately improved mine closure outcomes. Consequently, there is a growing need to provide early predictive information of intrinsic rock characteristics likely to impact on environmental performance and management throughout life of mine phases, including mine closure. The objectives of this contribution are to review predictive environmental indicators for AMD and to illustrate our advances in knowledge and the challenges ahead.

\section{$2 \quad$ Environmental indicators for AMD}

\subsection{First observations on AMD}

The knowledge that sulfide minerals oxidise at the Earth's surface and that this process causes the formation of secondary minerals and sulfuric acid is not new to modern science. Early civilisations of Sumeria, Assyria and Egypt, as well as Greek and Roman scholars, were familiar with the salts formed from the oxidation of pyrite (Karpenko and Norris, 2002).

Today, the control and mitigation of AMD is considered to be one of the major environmental challenges facing the mining industry worldwide (International Network for Acid Prevention, 2012). This pollution process has a long history dating back thousands of years, when the Rio Tinto mining district of Spain experienced periods of intense mining and the associated production of pyrite-rich wastes and AMD waters (Figure 1).

At Rio Tinto, mining is not entirely responsible for the generation of AMD and its impact on the river (Lottermoser, 2010). Historical records refer to the river's long-standing acidity. The Romans called the Rio Tinto 'urbero', Phoenician for 'river of fire', and the Arab name for it was 'river of sulfuric acid'. The gigantic sulfide orebodies experienced long-term weathering and erosion at some stage in their geological history and, acid weathering of outcropping sulfide ores likely produced natural AMD prior to mining. Thus, the river's conditions today are a combination of natural and mining-induced AMD.

The very first ground-breaking observations on $A M D$ and the use of indicators to understand AMD processes at mine sites were documented by Diego Delgado, a 16th century priest, who inspected the Rio Tinto mines and river (Salkield, 1987). In 1556, Diego Delgado reported on the state of the Rio Tinto mining district and recognised: (a) that pyrite oxidation leads to the formation of AMD products, including sulfuric acid; (b) that iron dissolves in AMD waters; (c) that iron hydrolyses and forms iron-rich cements in stream sediments; (d) that AMD waters are toxic to fish and other aquatic organisms; and (e) that simple experiments can reveal the ecotoxicity of AMD waters (Salkield, 1987). In doing so, Diego Delgado became one of the first scholars, if not the first, to use environmental indicators as tools to understand AMD and its impacts.

\subsection{Today's environmental indicators for AMD}

Since the first scientific observations on AMD processes by Diego Delgado hundreds of years ago, we have gained some phenomenal knowledge on AMD indicators and their application in life of mine planning. Most importantly, the scientific community has achieved a detailed understanding of the weathering reactions 
that cause sulfide oxidation and AMD development. Consequently, numerous quantitative tests and indicators have been designed to predict AMD (Table 1).

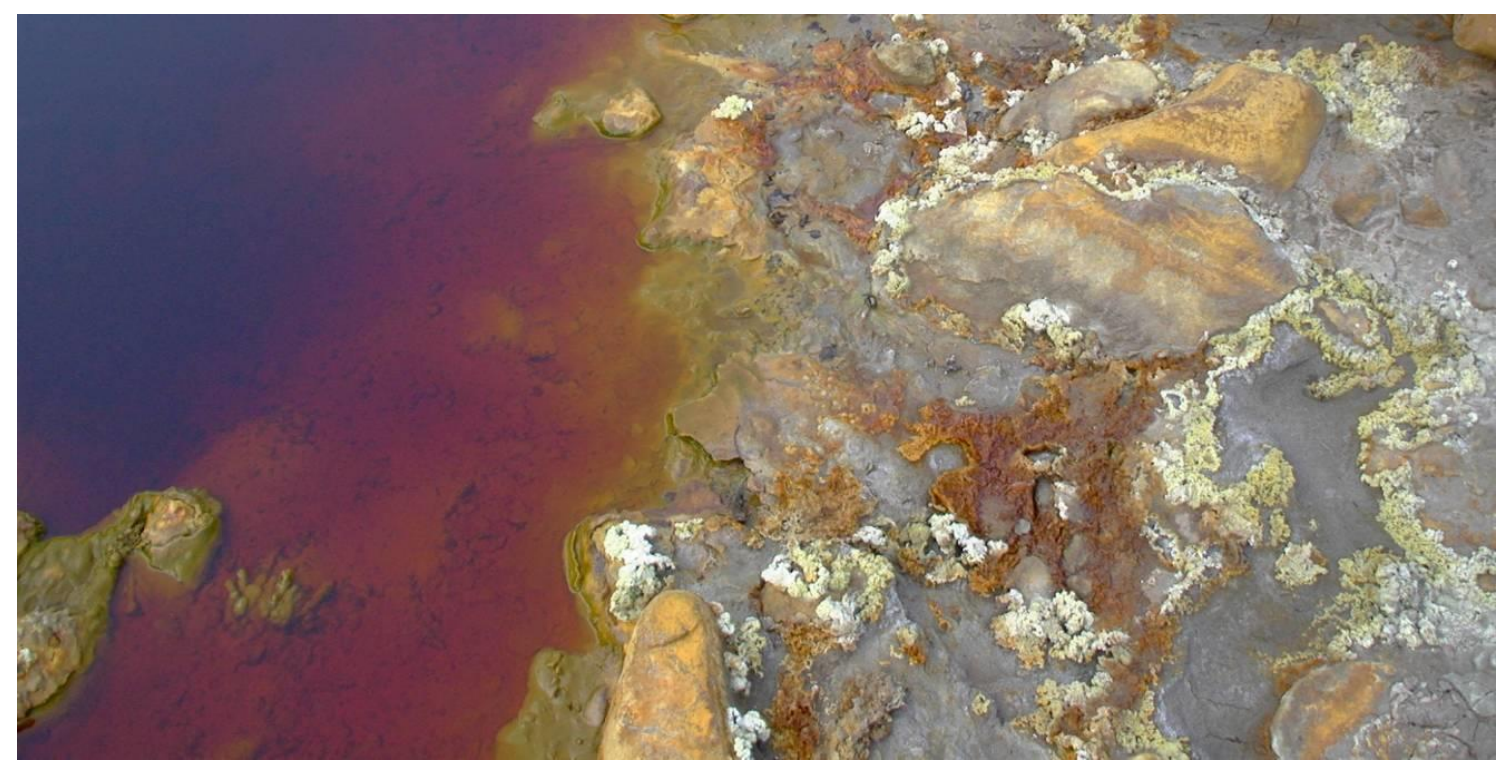

Figure 1 AMD waters in the Rio Tinto mining district, Spain. Multicoloured efflorescent sulfate minerals have precipitated along the river bank. Field of view about $2 \mathrm{~m}$ on horizontal axis of photo

Table 1 Examples of environmental indicator tests that provide information on AMD generation

\begin{tabular}{ll}
\hline Information on AMD Generation & Example of Environmental Indicator Tests \\
\hline $\begin{array}{l}\text { Indication of the acid-forming potential } \\
\text { of rocks, ores and wastes. }\end{array}$ & $\begin{array}{l}\text { Static tests, e.g. maximum potential acidity, acid neutralisation } \\
\text { capacity, paste and rinse pH, net carbonate value, acid } \\
\text { buffering characterisation curve, net acid generation tests. }\end{array}$ \\
$\begin{array}{l}\text { Leachate characteristics of rocks, ores } \\
\text { and wastes in the long term. }\end{array}$ & $\begin{array}{l}\text { Kinetic tests, e.g. humidity cells, column leach tests, Soxhlet } \\
\text { extraction tests, British Columbia Research Confirmation } \\
\text { (BCRC) test, shake flask, and field tests. }\end{array}$ \\
\hline
\end{tabular}

At present, routine prediction of sulfide oxidation and AMD is based on geochemical analyses. Such approaches range from static laboratory-based methods to kinetic trials (Table 1). The most widely used static method quantitatively balances the acid generated from the oxidation of sulfides against the acid consumption of carbonates and other minerals. Numerous static tests have been developed but all of them are rapid (usually measured in hours and days), low-cost screening tests to evaluate particular samples (Price, 2009). The most basic static test procedure acid-base accounting (ABA) requires: (i) the measurement of total or sulfidic sulfur and calculation of the maximum potential acidity (MPA); and (ii) the measurement of the acid neutralising capacity (ANC). The difference between these values gives an indication of the acid-forming potential of a waste material. Although static geochemical assessment can identify potential AMD issues, the use of these methods to determine whether the acid and metal release will occur is limited. This is largely due to the fact that static tests have inherent limitations and do not consider mineral dissolution rates and associated acid production and consumption. There can be considerable lag time between the atmospheric exposure of sulfidic materials and the onset of AMD.

The greatest criticism of existing static tests is the vast differences between laboratory testing conditions and site conditions. Consequently, a variety of simulated kinetic weathering tests have been developed and studied as drainage quality predictors, e.g. humidity cells, column leach tests, soxhlet extraction, etc (Price, 2009; Parbhakar-Fox and Lottermoser, 2011). Kinetic tests subject samples to dissolution either in the laboratory or the field. The details of kinetic tests differ, but all methods attempt to mimic cyclic 
wetting/drying and flushing of wastes. In general, kinetic tests involve the subjection of samples to periodic leaching, collection of drainage for analysis, calculation of rates of acid formation, calculation of rates of metal release, and the prediction of water quality. This is generally undertaken by simulating or accelerating the natural weathering rate of a sample under closely controlled conditions. Kinetic tests are used to: (i) verify static test data; (ii) identify the dominant chemical weathering reactions; (iii) determine acid-formation rates and assess AMD potential; (iv) provide insights into when acid production of a particular sample is likely to occur; ( $v$ ) predict chemical composition and temporal variation in leachate quality; and (vi) estimate the release rate of environmentally significant elements and compounds from rock materials (White et al., 1999).

A drawback of kinetic tests is the extended amount of time required to perform the tests, as it is not uncommon for these tests to continue for at least 26 weeks and preferably much longer (White et al., 1999). There are further limitations with laboratory based kinetic tests which chiefly involve the fact that calculated rates of acid formation, neutralisation and metal release may not be representative of the geological material in the field. One of the greatest challenges in laboratory kinetic testing is the successful upscaling of results to field scale. Currently, there is no consensus on which static method/test most accurately reflects field conditions. Questions have arisen regarding the length of laboratory test times and extrapolation to field weathering time. Additionally, there are limitations with laboratory conditions, including the equipment configuration and experimental conditions used, e.g. waste grain size. As a result, the data of laboratory kinetic tests cannot wholly be relied upon for the prediction of field water quality. Consequently, field-based kinetic tests should be established at mine sites as they represent the best approximation for the evolution of AMD (Lottermoser, 2010). However, these tests are costly, require 'site champions', rely on regular monitoring, and need to take place over long time scales (i.e. years).

Today's available prediction tools and analytical facilities combined with a proactive, well-informed approach and cautious interpretation of the results allow mine operators to meet environmental objectives and to minimise the liabilities and risks arising from waste disposal and mine drainages. Robust waste management plans can be developed and mine wastes can be fully characterised as part of the environmental impact statement with the future performance of the materials also predicted. Moreover, a number of publications are available documenting AMD prediction, prevention and remediation, including the industry-funded Global Acid Rock Drainage (GARD) Guide (GARD Guide, 2012), and a comprehensive Mine Environment Neutral Drainage (MEND) prediction manual for the drainage chemistry from sulfidic geological materials (Price, 2009).

\subsection{Consequences of failing to predict AMD}

Consequences of failing to predict and manage AMD for individual operations and for the mining industry include unplanned spending on remedial measures and reputational damage (Dowd, 2006). For large mines in settings favourable to the generation of $A M D$, unplanned closure costs have frequently been in the range of AS\$ 50-100 million, and sometimes beyond (Dowd, 2006). The estimated costs for total worldwide liability associated with the current and future remediation of AMD are approximately US\$100 billion (Tremblay and Hogan, 2001). Thus, regardless of the advancement in knowledge made and the wide range of tests available, there are numerous examples of mine sites from around the world, including Australia, that represent post-closure AMD liabilities.

\subsubsection{Mary Kathleen uranium mine site, Queensland}

The Mary Kathleen uranium mine site was rehabilitated between 1982 and 1985, which included the dry capping of a $9 \mathrm{Mt}$ tailings storage facility (Lottermoser and Ashley, 2005; Lottermoser et al., 2005). Rehabilitation of the site was completed in 1985 at a cost of some A\$19 million. In 1986, the Institute of Engineers Australia presented the company with an award for environmental excellence. In the past, the site has also been referred to as "a benchmark for the site clean-up of other mine sites in Australia and overseas, particularly in the uranium industry" (Cato, 1995) and "as an example of successful closure" (Allan, 1998). Today, and twenty five years after rehabilitation, it is evident that some rehabilitation measures 
have been quite successful in reducing dispersion of uranium and related elements into the surrounding environment (Lottermoser and Ashley, 2005; Lottermoser et al., 2005). By contrast, the predictions made on the geochemical behaviour of waste rock dumps and the tailings storage facility proved to be incorrect (Figure 2). In the 1980s, it was predicted using static and kinetic testing of tailings that: (i) the tailings porewaters would not infiltrate into the local aquifer; (ii) there would be little chance of AMD and of metal and radionuclide mobility from the repository; and (iii) seepage water quality would not pose a problem for human or stock health, despite sulfate contamination of the groundwater being the main long term environmental impact.

Today, there is still significant mobility of contaminants from the tailings storage facility into ground and surface waters, contaminants are being transferred into plants, and there is a threat to stock health (Lottermoser and Ashley, 2005; Lottermoser et al., 2005; Lottermoser, 2011). Seepage water from the tailings dam is slightly acid ( $\mathrm{pH} \mathrm{5.5),} \mathrm{metal-} \mathrm{and} \mathrm{sulfate-rich,} \mathrm{and} \mathrm{radioactive} \mathrm{(Figure} \mathrm{2).} \mathrm{Although} \mathrm{release}$ rates of uranium and other metal/metalloid contaminants from the tailings dam are small, concentrations of Total Dissolved Solids (TDS), uranium and sulfate in surface waters commonly exceed stock water quality guidelines (Lottermoser and Ashley, 2005). Physical erosion and chemical leaching of waste rock repositories and the leaching of the tailings repository are the dominant pathways of contaminants into surrounding environments (Lottermoser and Ashley, 2005; Lottermoser et al., 2005). The Mary Kathleen tailings repository is an example where good intent to achieve appropriate waste management and encapsulation of wastes was rendered ineffective. Unrepresentative sampling of tailings for testing purposes, insufficient waste characterisation and inadequate installation of the dry cover upon mine closure led to an ineffective encapsulation of tailings and resultant long-term water quality impacts on ground and surface waters.

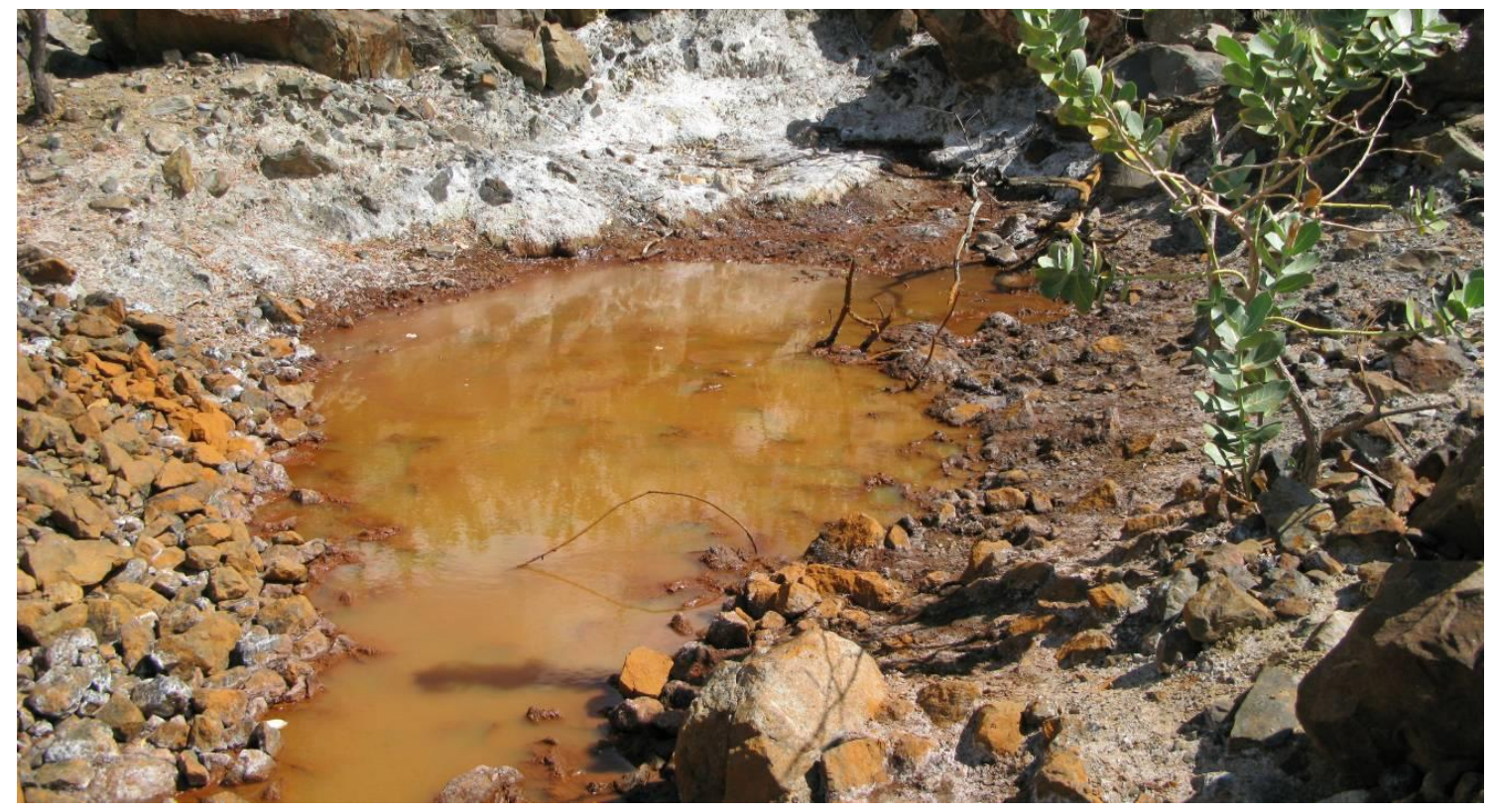

Figure 2 AMD seepage waters emanating from the capped and rehabilitated tailings storage facility of the Mary Kathleen uranium mine, Queensland

\subsubsection{Gold mine site, north Queensland}

At a north Queensland gold mine, a large waste rock dump was used as a receptacle for $15 \mathrm{Mt}$ of waste rock material from open pit and underground gold mining activities from 1987 to 1992 . The dump was a purpose-built, designed and rehabilitated landform, occupying approximately 25 ha. The design of the dump included a central core of selectively placed primary sulfidic waste $(6 \mathrm{Mt})$, within basal and perimeter layers of oxide waste and an oxide waste cap $(9 \mathrm{Mt})$. The construction and design of the dump aimed to minimise future liabilities by designing a waste repository that conformed to acceptable environmental 
standards. In the early 1990s, the waste repository design received an award for excellence from the Queensland State Government.

Today, leaching of surface wastes and resultant contamination of the local groundwater and creek systems, gully erosion of fine-grained batters, and exposure of a sulfidic layer in the waste dump batter remain post-rehabilitation concerns. This particular legacy issue has arisen because twenty years ago the operator at that time did not pursue best practices in the environmental management of waste rocks and committed a number of fundamental waste management errors, including the following:

1. Pursuit of a flawed waste rock dump design. The original waste repository design aimed to encapsulate sulfide waste in oxide waste. This rather simplistic approach implied that oxide waste was benign and did not contain any sulfides. However, the oxide waste cover contains minor amounts of sulfides and has a minor acid-generating capacity.

2. Inadequate waste characterisation and classification during mining and waste disposal. During operation, waste characterisation and classification were based on visual observations and segregation into two waste types: oxide and sulphide waste. However, many waste rock types contained minor amounts of small-grained sulfides and the simplistic waste segregation into two different types did not consider the mineralogical and geochemical diversity of the deposit, despite the fact that the deposit was enclosed by six different known waste rock types. Moreover, detailed waste characterisation, using best practice available at that time such as adequate sampling for comprehensive geochemical static testwork and mineralogical characterisation, was not pursued.

3. No control of civil engineering works upon waste rock dump construction. The designed repository was not built to specifications. A sulfidic waste layer ( $80-120 \mathrm{~m}$ long, $2.5 \mathrm{~m}$ thick) is currently exposed to atmospheric leaching. Also, fine-grained waste batters should have been armoured with boulders.

The dump is another example where good intent to achieve appropriate waste management and encapsulation of acid-generating wastes was rendered unsuccessful. A flawed repository design, inadequate waste management practices, and poor supervision of contractors have led to physical instability of waste rock batters, ineffective encapsulation of potentially acid-forming (PAF) materials, exposure of PAF materials, and resultant water quality impacts on ground and surface waters.

\subsubsection{Reasons for failing to predict AMD}

The scientific literature is replete with studies on sulfide oxidation, as well as the chemical reactions and processes leading to AMD development (Lottermoser, 2010). Scientists have made some phenomenal advances in their ability to observe, describe, quantify and predict sulfide oxidation. Despite these scientific advances, AMD closure liabilities continue to occur. The reason for this discrepancy appears to be multi-fold:

1. Environmental management of mineral resources is still a reactive activity, focussing on compliance and monitoring. This is despite the fact that best practice should pursue predictive AMD test works at the exploration and pre-feasibility stages of mineral resource development.

2. AMD risk assessments rely on too few predictive static and kinetic tests, with the inherent geological variability hardly considered, and statistically sound AMD block models are hardly ever prepared.

3. Waste classifications rely on simplistic static tests to categorise materials as PAF and non-acid-forming (NAF) wastes. This is despite the fact that such basic tests do not consider imperative variables that influence sulfide oxidation and AMD production over time, e.g. weathering reaction rates of individual minerals, presence or absence of particular micro-organisms, mineral and waste particle size, texture, mineral chemistry, formation of 
secondary minerals, waste temperature, pore gas composition and concentrations, preferential flow paths, or climatic effects.

4. The existing static tests, are meant to be screening tools for preliminary waste classification. Nevertheless, industry relies on static tests to decide on large-scale waste management and disposal.

5. Kinetic tests including onsite leach trials and field trial dumps, are required to gain an all-inclusive understanding of AMD and neutral mine drainage generation. Nonetheless, such long-term trials are rarely pursued on mine sites.

6. Notable uncertainty exists in the long-term AMD predictions. Evaluation of environmental impact statements from 25 mines in the United States showed that 15 of 25 mines (60\%) exceeded surface water quality standards for metals and pH after permitting (Jennings et al., 2008).

7. Tailings and waste rock repositories are not built in accordance with waste repository designs and mine closure plans. Specifically, the capping of waste repositories, the characterisation of capping materials and the placement of wastes into repositories need much more attention by contractors and operators.

8. Monitoring of waste disposal into repositories is minimal during operation.

9. Rehabilitated waste repositories and their covers represent poorly understood, young landforms that have not equilibrated with the surrounding landscape, i.e. in terms of weathering and leaching rates.

10. There is little knowledge on how native vegetation interacts with the covers of waste repositories and allows access of oxygen and water to capped sulfidic wastes at depth.

11. To date, static AMD tests for waste and drainage prediction have been accurate in some cases and misleading in others. The reason for this failure appears to be partly because the existing static tests have inherent limitations (White et al., 1999).

\subsection{Future environmental indicators for AMD}

Accurate prediction of sulfide oxidation and AMD processes still represents a challenging concept for scientists because of the complex mineralogical, geochemical and microbiological processes leading to AMD. The route to greater confidence in the prediction of AMD processes is not through more sophisticated modelling of weathering reactions and leach behaviours. Our skills at modelling have run ahead of our understanding of the mineralogical, geochemical and microbiological processes leading to AMD and our ability to test models against real data from the laboratory and the field.

Improvements in prediction will come from carefully designed and validated laboratory tests and better understanding of the underlying AMD processes at individual mine sites. Research therefore needs to continue on improving predictive static tests and methods. In particular, cost-effective static tests need to be developed that consider or speed up weathering time, address the known limitations of existing static testing procedures, and ultimately represent, more accurately, the actual waste behaviour in the long term and real field conditions. Also, AMD risk assessments need consider predictive geochemical test data but also mineralogical and textural aspects of sulfidic rock materials (Parbhakar-Fox et al., 2011). Moreover, a staged approach to AMD risk assessment and associated screening of different sample types allows a more cost-effective identification of AMD risks associated with specific rock types (Parbhakar-Fox et al., 2011).

\section{$3 \quad$ Mine closure plans}

Mine closure planning involves the effective planning for a designated post-mining land use. Planning documents should state closure objectives and standards, reclamation goals and methods, and long-term predictions on aspects such as waste repository behaviour, landscape performance and vegetation covers. 
Predictive environmental indicators should be an integral part of such plans, providing information on the physical, chemical and biological environment including waste behaviour, effluent discharges, soil quality, erosion rates and ecosystem success, and increasingly a risk-based estimation of climate change effects on AMD generation and mine site runoff water quality (Nordstrom, 2009; Rayne et al., 2009). For example, variable precipitation and seasonal run-off will disrupt water supplies, affect water quality and increase the risk of uncontrolled AMD discharge. Environmental indicators form the basis for long-term site predictions, which in turn allow appropriate life of mine costing, the development of closure strategies, scenarios and plans, and the identification of additional research needs and remediation efforts.

Despite the advances in knowledge on environmental indicators and their application in mine closure planning, today's mine closure plans tend to be verbose, vague and diffuse documents. Such documents rarely tabulate actual scientific analyses, hardly ever rely on environmental indicators, or even attempt an understanding of environmental processes. As a result, verbose mine closure plans do not deliver successful mine closure and a safe return of mine site domains to future land use. Typically, long-term legacies such as AMD, poor water quality, land instability, soil contamination, weed invasion, and public safety hazards remain. Such legacies require ongoing site maintenance and ownership.

In future, mine closure planning should learn from strategic and tactical planning in the military (Vincent, 2011). The German Field Marshall Helmuth Karl Bernhard Graf von Moltke was one of the great strategists of the 19th century and the creator of more modern strategies and tactics. He recognised the dynamic nature of plans, tactical manoeuvrers and strategic decisions, and stated "No battle plan survives first contact with the enemy", Grosser Generalstab (1900). Similarly, current verbose and vague mine closure plans do not survive first contact with actual, real-life mine closure challenges. The increasing complexity and scale of mine closure, together with improving environmental knowledge, greater social expectations and legal requirements, may force the regulator and industry to test the robustness of closure plans and the predictive knowledge of environmental indicators they generate. A thorough evaluation of closure tactics could lead to much improved mine closure. In doing so, environmental pollution and degradation would become the 'hostile force' and environmental protection the goal as 'victory' in a 'battle' for sustainability.

For example, gigantic AMD legacies such as South Africa's Witwatersrand region necessitate key players (government, mining companies, researchers, communities, consultants) to get the facts on the table and collectively deliver workable and cost-effective solutions without fear or favour (Vincent, 2011). This can only be achieved if a solid scientific understanding of current and future environmental processes is presented to all stakeholders. Environmental indicators provide the facts and are the key tools to reveal environmental risks and processes.

In future, mine closure plans should: (a) contain less verbiage and fragmented environmental knowledge; (b) be tested for their closure tactics; (c) be validated whether they will actually deliver real closure outcomes; and (d) contain scientific data and environmental indicators that have been collected from the exploration stage onwards. Such improvements would lead to more realistic closure objectives, more quantitative performance measures, more measurable closure outcomes, validated closure tactics, fewer environmental risks, and ultimately reduced financial liabilities.

\section{$4 \quad$ Conclusions}

Prediction is one of the basic desires of humanity, to discern the future and know what fate holds. More than ever, scientists have important contributions to make as they design and validate environmental indicators and provide the data necessary for rational decision-making, including mine closure and the formulation of closure plans.

The most urgent problems facing scientists working on AMD indicators are:

1. Validating existing AMD indicator tests and their applicability for forecasting environmental conditions at mine sites. 
2. Designing better $A M D$ indicator tests that accurately predict environmental processes in the long term.

3. Providing assistance in the preparation of much improved mine closure plans that represent less verbose documents, containing fragmented environmental knowledge. Instead, closure plans should rely on scientific data and a knowledge of environmental processes acquired at the mine site, including the early use of AMD indicators.

There is reason for optimism that the required progress is possible. Such optimism is based on the phenomenal advances in our ability to observe and describe AMD processes. However, focussed efforts are necessary if we are to develop innovative AMD tests and risk assessment protocols, as well as improved mine closure plans.

\section{Acknowledgement}

The author acknowledges the support of CRC ORE, established and supported by the Australian Government's Cooperative Research Centres Programme.

\section{References}

Allan, J.G. (1998) Decommissioning in the Australian mining industry setting the scene, in Proceedings of Workshop on Environmental Issues in Decommissioning of Mine Sites, C.J. Asher and L.C. Bell (eds), 9-10 March 1998, Brisbane, Queensland, Australian Centre for Mining Environmental Research, Kenmore, Australia, pp. 1-9.

Asher, C.J. and Bell, L.C. (eds) (1998) Proceedings of the Workshop on Indicators of Ecosystem Rehabilitation Success, Australian Centre for Mining Environmental Research, Kenmore, Australia, $151 \mathrm{p}$.

Cato, L. (1995) The integration of environmental research and technology in the mining industry-case histories from CRA, The Business of Ecology: Australian Organisations Tackling Environmental Issues, L. Cato (ed), Allen \& Unwin, Sydney, Australia, pp. 62-67.

Dowd, P.J. (2006) The business case for the prevention of acid drainage, in Proceedings of the 5th Australian Workshop on Acid and Metalliferous Drainage, L.C. Bell and R.W. McLean (eds), 29-31 August, Fremantle, Western Australia, Australian Centre for Minerals Extension and Research, Kenmore, Australia, pp. 1-10.

GARD Guide (2012) Global Acid Rock Drainage Guide, Viewed 5 May 2012, http://www.gardguide.com.

Grosser Generalstab (ed) (1900) Moltkes Militaerische Werke, E.S. Mittler und Sohn, Berlin, Vol. 2, Part 2, pp. 33-40 (in German).

International Network for Acid Prevention (INAP) (2012), Viewed 5 May 2012, http://www.inap.com.au.

Jasper, D. (2007) Rehabilitation: Indicators and monitoring, Encyclopedia of Soil Science, W. Chesworth (ed), Taylor \& Francis, Abingdon, UK, pp. 1460-1463.

Jennings, S.R., Neuman, D.R. and Blicker, P.S. (2008) Acid mine drainage and effects on fish health and ecology: A review, Reclamation Research Group Publication, Bozeman, MT, United States, 29 p.

Karpenko, V. and Norris, J.A. (2002) Vitriol in the history of chemistry, Chemicke Listy 96, pp. 997-1005.

Lottermoser, B.G. (2010) Mine wastes: Characterization, treatment, and environmental impacts, 3rd edition, Springer-Verlag, Berlin Heidelberg, $400 \mathrm{p}$.

Lottermoser, B.G. (2011) Colonisation of the rehabilitated Mary Kathleen uranium mine site (Australia) by Calotropis procera: Toxicity risk to grazing animals, Journal of Geochemical Exploration, Vol. 111, pp. 39-46.

Lottermoser, B.G. and Ashley, P.M. (2005) Tailings dam seepage at the rehabilitated Mary Kathleen uranium mine, Australia, Journal of Geochemical Exploration 85, pp. 119-137.

Lottermoser, B.G., Ashley, P.M. and Costelloe, M.T. (2005) Contaminant dispersion at the rehabilitated Mary Kathleen uranium mine, Australia, Environmental Geology 48, pp. 748-761.

Nordstrom, D.K. (2009) Acid rock drainage and climate change, Journal of Geochemical Exploration Vol. 100, pp. 97-104.

Parbhakar-Fox, A. and Lottermoser, B.G. (2011) Predictive Environmental indicators in mining: Review of the literature and current best practices, Technical Report No. 2, Cooperative Research Centre for Optimising Resource Extraction, Brisbane, Australia, $142 \mathrm{p}$.

Parbhakar-Fox, A., Edraki, M., Walters, S. and Bradshaw, D. (2011) Development of a textural index for the prediction of acid rock drainage, Minerals Engineering, Vol. 24, pp. 1277-1287.

Price, W.A. (2009) Prediction manual for drainage chemistry from sulphidic geologic materials, MEND report 1.20.1, CANMET Mining and Mineral Sciences Laboratories, Smithers, Canada, 579 p.

Rayne, S., Forest, K. and Friesen, K.J. (2009) Analytical framework for a risk-based estimation of climate change effects on mine site runoff water quality, Mine Water and the Environment 28, pp. 124-135.

Salkield, L.U. (1987) A technical history of the Rio Tinto mines: Some notes on exploitation from pre-Phoenician times to the 1950s, The Institution of Mining and Metallurgy, London, UK, $114 \mathrm{p}$.

Tremblay, G.A. and Hogan, C.M. (eds) (2001) Mine Environment Neutral Drainage (MEND) Manual 5.4.2d: Prevention and Control, Canada Centre for Mineral and Energy Technology, Natural Resources Canada, Ottawa, 352 p. 
challenges ahead

Vincent, M. (2011) War gaming may just be the answer to solving South Africa's own Chernobyl, Deloitte, viewed 5 May 2012, www.deloitte.com.

White III, W.W., Lapakko, K.A. and Cox, R.L. (1999) Static test methods most commonly used to predict acid mine drainage: practical guidelines for use and interpretation, The Environmental Geochemistry of Mineral Deposits Part A: Processes, Techniques, and Health Issues, G.S. Plumlee and M.J. Lodgson (eds), Reviews of Economic Geology, Vol. 6A, Society of Economic Geologists, Littleton, United States, pp. 325-338. 